\title{
Severe aortic stenosis in elderly patients
}

\author{
EVA NYLANDER, * INGER EKMAN, * TAGE MARKLUND, $\dagger$

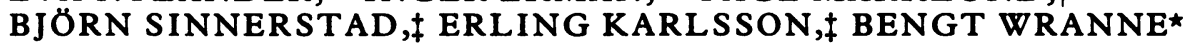

From the Departments of ${ }^{\star}$ Clinical Physiology, $†$ Diagnostic Radiology, and $\ddagger$ Medicine, Division of Cardiology, University Hospital, Linköping, Sweden

SUMMARY Clinical and non-invasive findings were compared with catheterisation data in 91 elderly patients (mean 65 years, range 52-78) with suspected severe aortic stenosis requiring operation. Heart catheterisation showed that forty nine patients had a valve area of $\leqslant 0.6 \mathrm{~cm}^{2}, 36$ had a valve area of $0 \cdot 7-1 \cdot 0 \mathrm{~cm}^{2}$, and six an area of $\geqslant 1 \cdot 1 \mathrm{~cm}^{2}$. Coexistent aortic regurgitation was found in $85 \%$ of the cases, but severe regurgitation was found in only one patient $(1 \%)$. Seventy seven per cent of patients had chest pain, $74 \%$ had dyspnoea, and $46 \%$ had exertional vertigo or syncope. Coronary angiography, which was performed in 77 patients, showed coronary artery disease in $24 \%$ of those with a history of angina pectoris and in none of those without. All patients had echodense valves; aortic valve calcification was shown by $x$ ray in $76 \%$ and in all but one by cineradiography. The peak of the systolic murmur was delayed in $98 \%$ of the patients. Although a prolonged left ventricular ejection time was characteristic of severe aortic stenosis, a normal value did not exclude this diagnosis. Most patients (84\%) had increased QRS amplitude on the electrocardiogram. Echocardiography showed an increased left ventricular wall thickness in $90 \%$ of the patients in whom it was possible to define the myocardial borders. There was an inadequate blood pressure increase in response to exercise in $82 \%$. In about $25 \%$ of the patients the exercise test was at variance with the New York Heart Association classification. Findings suggesting severe aortic stenosis resembled those reported for younger age groups. When most findings point to severe aortic stenosis, the absence of a single symptom or non-invasive sign does not exclude severe aortic stenosis.

The classic symptoms of aortic stenosis-congestive heart failure, angina pectoris, and syncope-usually appear in the sixth decade or later ${ }^{12}$ and without operation outcome is usually poor. Operation on elderly patients with aortic stenosis is now feasible. Studies of the diagnosis and haemodynamics of aortic stenosis have mainly been of younger patients with isolated aortic stenosis; patients with coexistent aortic regurgitation have been excluded. Usually only single non-invasive signs have been investigated, and of those studies in which a combination of non-invasive variables was used to predict the severity of aortic stenosis ${ }^{3-6}$ only one ${ }^{6}$ included echocardiography and none included an exercise test.

In our experience isolated aortic stenosis is rare in

Requests for reprints to Dr Bengt Wranne, Department of Clinical Physiology, Regionsjukhuset, S-581 85 Linköping, Sweden.

Accepted for publication 2 December 1985 elderly patients. Because coexistent ischaemic heart disease is common, coronary angiography has seemed to be essential, although it was reported as being carried out in only one of the above mentioned studies. ${ }^{6}$ Our study describes the haemodynamic, clinical, and non-invasive features in a group of elderly patients referred for catheterisation because they were believed to have aortic stenosis severe enough to merit operation.

\section{Patients and methods}

The patients who fulfilled the above criteria were all $>50$ years old and numbered 94 , but three of them have been excluded because their aortic valve area could not be determined at catheterisation. The remaining 91 comprised 38 women and 53 men aged 52-78 years (mean 65). Figure 1 shows the functional capacity of the 91 patients according to New York Heart Association criteria. ${ }^{7}$ Eighteen patients 480 


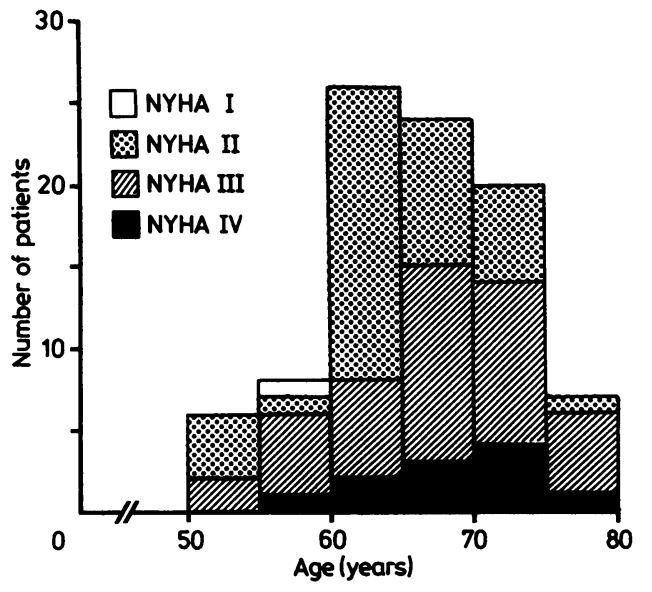

Fig. 1 New York Heart Association classification in relation to age.

were or had been on maintenance antihypertensive medication. Forty four patients were on digitalis, 51 on diuretics and 23 on $\beta$ blockers.

\section{Methods}

Patient history was extracted from the medical records with particular emphasis on effort-related chest pain, dyspnoea, dizziness, and syncope. A 12 lead electrocardiogram was recorded at rest and evaluated according to the Minnesota Code. ${ }^{8}$ An exercise test was performed with the patient seated on an electrically braked bicycle ergometer with either a stepped increase in load every sixth minute $(n=44)$ or with a continuous increase in workload of $10 \mathrm{~W}$ each minute $(n=32)$. Chest pain, dyspnoea, dizziness, fall in systolic blood pressure, or fatigue were used as end points. With the stepped increase in workloads, maximal work performance (Wmax $6^{\prime}$ ) was calculated according to Strandell. ${ }^{9}$ With the continuous load increase, the workload at the interruption of the test was converted into $W \max 6^{\prime}$ by multiplication by a factor of $0 \cdot 78 .^{10}$

Indirect systolic blood pressure response during exercise was classified as: I a fall of $\geqslant 10 \mathrm{~mm} \mathrm{Hg}$; II a subnormal rise, that is $\leqslant 10 \mathrm{~mm} \mathrm{Hg}$ per $30 \mathrm{~W}$ increase in workload; III a normal rise, that is 11 to $30 \mathrm{~mm} \mathrm{Hg}$ rise per $30 \mathrm{~W}$. Phonocardiography was performed from the apex in the left lateral position (A) and from the base of the heart, where the murmur was strongest (B). The maximum of the systolic ejection murmur was defined and assessed in relation to the onset of the $Q$ wave and to the onset of the first heart sound $\left(S_{1}\right)$. These time intervals were subsequently related to the $Q-S_{2}$ and $S_{1}-S_{2}$ times respectively. The third and fourth heart sounds were regarded as abnormal if they had increased amplitudes relative to second heart sound $\left(S_{2}\right)$ and had a higher frequency content than normal. The carotid pulse was recorded with a system time constant of $3.2 \mathrm{~s}$ at a paper speed of $100 \mathrm{~mm} / \mathrm{s}$ simultaneously with the electrocardiogram (lead II). Left ventricular ejection time was measured and rate corrected in three different ways. ${ }^{11-13}$ The $T$ time and $U$ time were measured according to Tavel ${ }^{14}$ and were corrected according to Bazett. ${ }^{12}$

All chest radiographs and cineangiograms were examined retrospectively in sequence by one experienced radiologist without knowledge of other patient data. Aortic valve calcification was independently estimated from the chest $x$ rays and the cineangiography. Left ventricular angiography was performed in all patients, retrograde thoracic aortography in 87, and selective coronary angiography in 77. Aortic regurgitation was assessed semiquantitatively according to Cullhed ${ }^{15}$ and mitral regurgitation in a similar manner.

The echocardiograms, which had been recorded at routine clinical examination, were checked and remeasured by an experienced technician who was unaware of the catheterisation results. All measurements were obtained from $M$ mode recordings made with a $3 \mathrm{MHz}$ ATL (Advanced Technology Laboratory) mechanical sector scanner with the patient recumbent in the left lateral position, according to the recommendations of the American Society of Echocardiography. ${ }^{16}$ Left ventricular muscle mass was determined according to Bennett and Evans. ${ }^{17}$

All patients were catheterised, with a transseptal catheter to the left ventricle, one catheter to central aorta, and a third one to the pulmonary artery. Pressures were registered by external pressure transducers with the mid-thoracic level as a reference point. Cardiac output was determined by the Fick method. Simultaneous aortic and left ventricular pressures were recorded during the cardiac output determination and the aortic valve area was calculated by the Gorlin formula. ${ }^{18}$

\section{Statistics}

One way analysis of variance was performed to determine the statistical significance of observed differences between the three severity groups (see below). If a significant $F$ ratio was obtained, differences between each pair of group means were compared by Duncan's new multiple range test. ${ }^{19}$ Linear regression coefficients were calculated by the method of least squares. Multiple regression analysis, as expected, yielded no useful relations for the evaluation of the severity of the aortic stenosis because of the uniformity of these selected patients. 


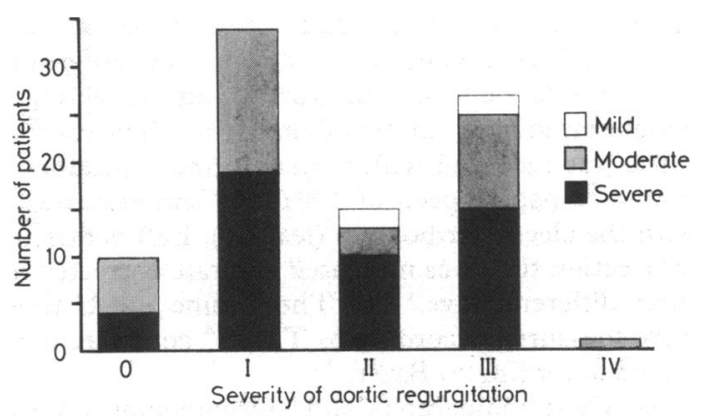

Fig. 2 Aortic regurgitation in relation to aortic valve area. Aortic regurgitation was assessed semiquantitatively according to Cullhed, ${ }^{15}$ where 0 is no regurgitation and $I V$ is severe regurgitation. Aortography was not performed in four cases.

\section{Results}

\section{Classification}

The patients were classified according to the severity of their aortic stenosis. Forty nine patients $(54 \%)$ (age 52-78, mean 67 years) were classified as having

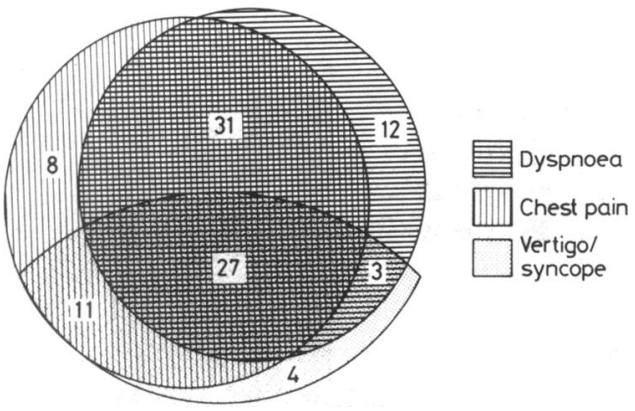

Fig. 3 Occurrence of dyspnoea, chest pain, and dizziness/syncope. Three of the 91 patients had no symptoms and are not included in the figure.

severe stenosis (aortic valve area $\leqslant 0.6 \mathrm{~cm}^{2}$ ), $36(39 \%)$ (age 53-76, mean 63), as having moderate stenosis (area $0.7-1.0 \mathrm{~cm}^{2}$ ), and six (7\%) (age 61-71, mean 67 ) as having mild stenosis $\left(\right.$ area $\geqslant 1 \cdot 1 \mathrm{~cm}^{2}$ ). Seventy seven $(85 \%)$ of the patients had aortic regurgitation of varying degrees, but only one patient (1\%) had severe regurgitation (Fig. 2). No patient was excluded because of its presence (see Dis-

Table 1 Haemodynamic variables

\begin{tabular}{|c|c|c|c|c|c|}
\hline & Aortic stenosis & No & Mean & $S D$ & Range \\
\hline Aortic valve area $\left(\mathrm{cm}^{2}\right)$ & $\begin{array}{l}\text { Severe } \\
\text { Moderate } \\
\text { Mild }\end{array}$ & $\begin{array}{r}49 \\
36 \\
6\end{array}$ & $\begin{array}{l}0.48 \\
0.78 \\
1.63\end{array}$ & $\begin{array}{l}0 \cdot 10 \\
0 \cdot 10 \\
0.66\end{array}$ & $\begin{array}{l}0.2-0.6 \\
0.7-1.0 \\
1.2-2.9\end{array}$ \\
\hline Peak systolic gradient (mm Hg) & $\begin{array}{l}\text { Severe } \\
\text { Moderate } \\
\text { Mild }\end{array}$ & $\begin{array}{r}49 \\
36 \\
6\end{array}$ & $\star \star\left[\begin{array}{l}79 \\
44 \\
18\end{array}\right]_{\star \star}^{\star \star}$ & $\begin{array}{l}31 \\
19 \\
19\end{array}$ & $\begin{array}{c}31-171 \\
11-90 \\
0-45\end{array}$ \\
\hline Mean systolic gradient (mm $\mathbf{~ H g}$ ) & $\begin{array}{l}\text { Severe } \\
\text { Moderate } \\
\text { Mild }\end{array}$ & $\begin{array}{r}49 \\
36 \\
6\end{array}$ & $\star \star\left[\begin{array}{l}64 \\
39 \\
18\end{array}\right]_{\star \star}^{\star}$ & $\begin{array}{l}21 \\
14 \\
14\end{array}$ & $\begin{array}{c}28-124 \\
11-73 \\
2-33\end{array}$ \\
\hline $\begin{array}{l}\text { Left ventricular systolic pressure } \\
\text { (mm Hg) }\end{array}$ & $\begin{array}{l}\text { Severe } \\
\text { Moderate } \\
\text { Mild }\end{array}$ & $\begin{array}{r}49 \\
36 \\
6\end{array}$ & $\star \star\left[\begin{array}{l}211 \\
189 \\
164\end{array}\right]^{\star \star}$ & $\begin{array}{l}37 \\
28 \\
34\end{array}$ & $\begin{array}{l}125-305 \\
118-241 \\
110-204\end{array}$ \\
\hline $\begin{array}{l}\text { Left ventricular end diastolic pressure } \\
(\mathbf{m m ~} \mathbf{H g})\end{array}$ & $\begin{array}{l}\text { Severe } \\
\text { Moderate } \\
\text { Mild }\end{array}$ & $\begin{array}{r}49 \\
36 \\
6\end{array}$ & $\begin{array}{l}21 \\
18 \\
17\end{array}$ & $\begin{array}{l}9 \\
8 \\
5\end{array}$ & $\begin{array}{r}7-40 \\
7-40 \\
10-24\end{array}$ \\
\hline Right atrial mean pressure ( $\mathrm{mm} \mathrm{Hg}$ ) & $\begin{array}{l}\text { Severe } \\
\text { Moderate } \\
\text { Mild }\end{array}$ & $\begin{array}{r}49 \\
36 \\
6\end{array}$ & $\begin{array}{l}6 \\
6 \\
6\end{array}$ & $\begin{array}{l}4 \\
3 \\
2\end{array}$ & $\begin{array}{l}2-21 \\
1-18 \\
3-8\end{array}$ \\
\hline $\begin{array}{l}\text { Systolic pulmonary arterial pressure } \\
(\mathbf{m m ~ H g})\end{array}$ & $\begin{array}{l}\text { Severe } \\
\text { Moderate } \\
\text { Mild }\end{array}$ & $\begin{array}{r}49 \\
36 \\
6\end{array}$ & $\begin{array}{l}42 \\
36 \\
37\end{array}$ & $\begin{array}{r}20 \\
13 \\
6\end{array}$ & $\begin{array}{l}20-100 \\
20-74 \\
27-42\end{array}$ \\
\hline Arteriovenous oxygen difference (ml/l) & $\begin{array}{l}\text { Severe } \\
\text { Moderate } \\
\text { Mild }\end{array}$ & $\begin{array}{r}49 \\
36 \\
6\end{array}$ & $\begin{array}{l}57 \\
55 \\
57\end{array}$ & $\begin{array}{l}11 \\
13 \\
16\end{array}$ & $\begin{array}{l}39-92 \\
38-94 \\
44-86\end{array}$ \\
\hline Stroke volume (ml) & $\begin{array}{l}\text { Severe } \\
\text { Moderate } \\
\text { Mild }\end{array}$ & $\begin{array}{r}49 \\
36 \\
6\end{array}$ & $\star \star\left[\begin{array}{l}53 \\
64 \\
70\end{array}\right]^{\star}$ & $\begin{array}{l}14 \\
16 \\
24\end{array}$ & $\begin{array}{l}27-89 \\
23-96 \\
30-100\end{array}$ \\
\hline
\end{tabular}

${ }^{\star} p<0.05,{ }^{\star \star} p<0.01$ 


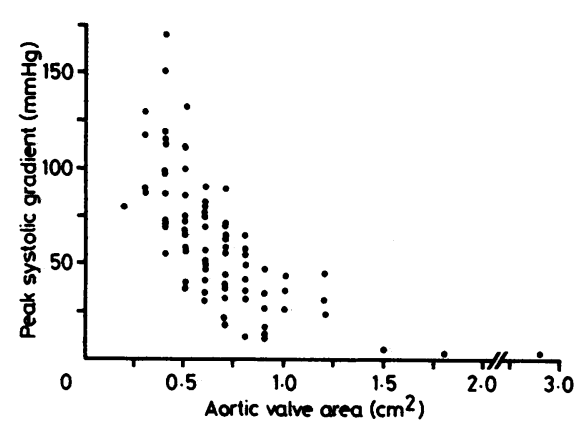

Fig. 4 Peak systolic gradient in relation to calculated aortic valve area. No correction was made for degree of aortic regurgitation.

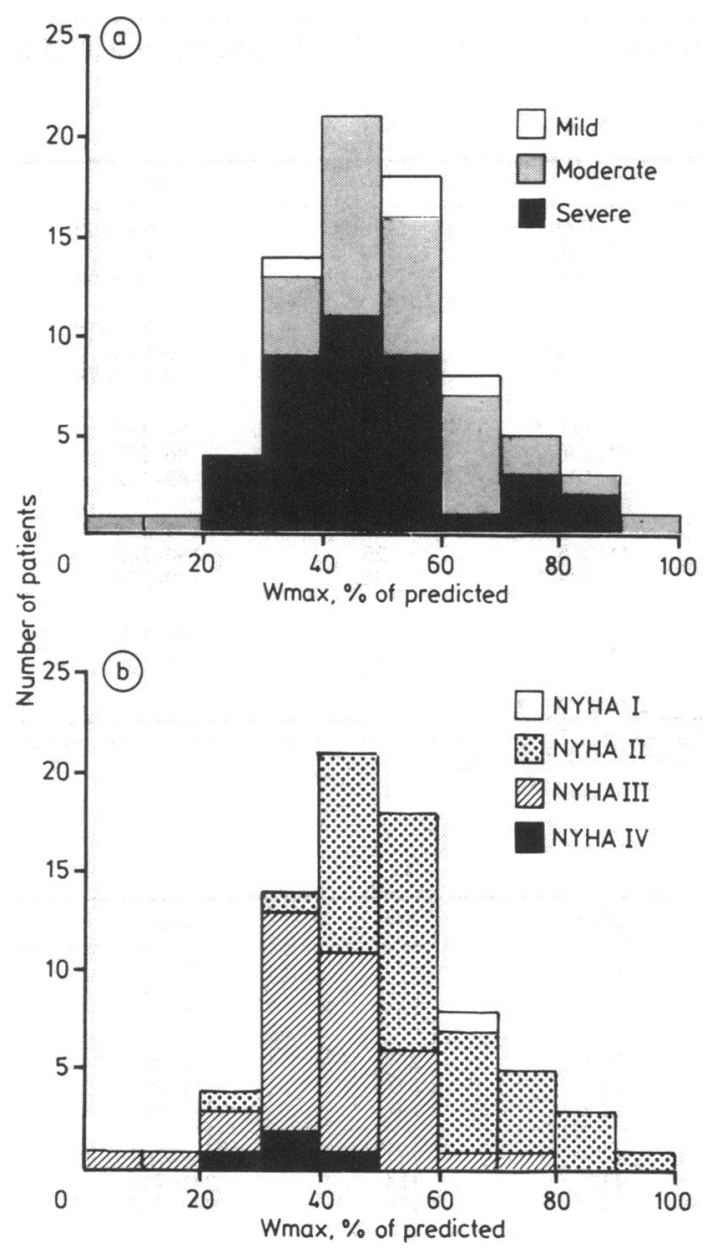

Fig. 5 Physical work capacity at the exercise test, expressed as per cent of age and sex related reference value $(W \max \%)^{21}$ in relation to aortic valve area $(a)$ and New York Heart Association classification (b). cussion). Twenty patients ( $22 \%$ ) had mild mitral regurgitation and nine $(10 \%)$ had moderate mitral regurgitation; these cases were equally distributed among the three aortic stenosis groups. Only two patients had severe mitral regurgitation-one in each of the groups with severe and moderate obstruction. The calculated aortic area forms the basis of the comparison with the non-invasive data.

\section{Symptoms}

Seventy patients $(77 \%)$ had a history of chest pain, $67(74 \%)$ of dyspnoea, and $42(46 \%)$ of vertigo and/or syncope, all related to exertion (Fig. 3). Twenty five patients $(27 \%)$ had a combination of all these symptoms and in 24 of these 25 patients the aortic valve area was less than $1 \cdot 1 \mathrm{~cm}^{2}$. Three patients, however, without any of these symptoms had the same small valve area.

\section{Findings at invasive investigation}

Table 1 summarises some variables that were determined invasively. As expected there is an inverse correlation between valvar area and systolic pressure gradient (Fig. 4). It is, however, notable that in individual patients with a peak systolic gradient of only $30 \mathrm{~mm} \mathrm{Hg}$ the valve area was less than $0.7 \mathrm{~cm}^{2}$. The stroke volume correlated with valve area. There was no significant difference between the three groups for most of the other invasive variables (Table 1).

\section{Electrocardiography}

The $\mathbf{R}$ amplitude criteria of left ventricular hypertrophy (Minnesota code 3.1 or 3.3) were fulfilled in $84 \%$ of the patients. One of the patients with a moderate stenosis had a normal electrocardiogram at rest. The remaining patients had left bundle branch block (four), signs of old infarction (two), pacemaker (one), or $\mathrm{T}$ wave abnormalities (seven).

\section{Exercise test}

An exercise test was performed by 76 patients ( $84 \%$ ) 37 of whom were in New York Heart Association functional class III or IV. There were no complications. The reasons for interruption of the exercise test were blood pressure reaction $(36 \%)$, chest pain $(29 \%)$, dyspnoea $(34 \%)$, vertigo $(3 \%)$, tiredness $(26 \%)$, other $(29 \%)$. Physical work capacity was reduced to below $80 \%$ of the reference value ${ }^{20}$ in $95 \%$ of the patients. Figure 5 shows the relation of the work capacity to valve area and to the New York Heart Association functional classification. Sixty two patients $(82 \%)$ had a subnormal blood pressure increase $(n=33)$ or a blood pressure reduction $(n=29)$ during the exercise test. Thirteen patients without a history of dizziness or syncope and with normal left ventricular ejection time had a subnor- 


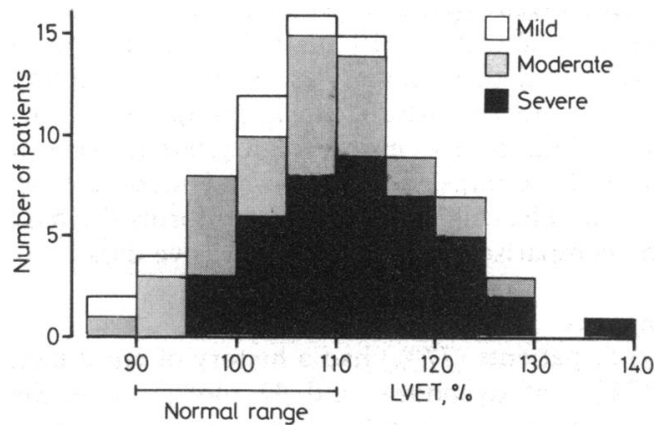

Fig. 6 Left ventricular ejection time corrected according to Meiners ${ }^{11}$ in relation to calculated aortic valve area.

mal blood pressure increase or a blood pressure reduction with this test.
Phonocardiogram and carotid pulse recording

As the valve area decreased the maximum of the murmur tended to come later in systole (Table 2), but this resulted in a significant difference only between the group with severe and that with mild stenosis and only at the apex. The fourth sound was abnormal in $25 \%$ of the patients; this sign was equally common in all three groups. Only $5 \%$ of the patients had an abnormal third heart sound. The left ventricular ejection time, $U$ time, and $T$ time were significantly longer for the group with severe stenosis compared with the groups with moderate and mild stenosis (Fig. 6, Table 2).

\section{Echocardiography}

In all patients echodensity was increased in the aortic valve region. Left ventricular wall thickness was increased in $44(90 \%)$ of the 49 patients in whom it

Table 2 Findings at phonocardiogram and pulse curve registrations

\begin{tabular}{|c|c|c|c|c|c|}
\hline & Aortic stenosis & No & Mean & $S D$ & Range \\
\hline QM2-A & $\begin{array}{l}\text { Severe } \\
\text { Moderate } \\
\text { Mild }\end{array}$ & $\begin{array}{r}39 \\
35 \\
6\end{array}$ & $\star\left[\begin{array}{l}0.66 \\
0.63 \\
0.58\end{array}\right.$ & $\begin{array}{l}0.06 \\
0.07 \\
0 \cdot 10\end{array}$ & $\begin{array}{l}0.53-0.82 \\
0.48-0.77 \\
0.44-0.68\end{array}$ \\
\hline QM2-B & $\begin{array}{l}\text { Severe } \\
\text { Moderate } \\
\text { Mild }\end{array}$ & $\begin{array}{r}44 \\
33 \\
6\end{array}$ & $\begin{array}{l}0.67 \\
0.65 \\
0.63\end{array}$ & $\begin{array}{l}0.05 \\
0.07 \\
0.11\end{array}$ & $\begin{array}{l}0.59-0.76 \\
0.47-0.79 \\
0.45-0.78\end{array}$ \\
\hline LVET (\%) & $\begin{array}{l}\text { Severe } \\
\text { Moderate } \\
\text { Mild }\end{array}$ & $\begin{array}{r}41 \\
30 \\
6\end{array}$ & $\star \star\left[\begin{array}{l}111 \\
106 \\
100\end{array}\right]^{\star \star}$ & $\begin{array}{l}9 \\
9 \\
9\end{array}$ & $\begin{array}{l}97-135 \\
86-127 \\
89-112\end{array}$ \\
\hline $\mathrm{U}$ time (ms) & $\begin{array}{l}\text { Severe } \\
\text { Moderate } \\
\text { Mild }\end{array}$ & $\begin{array}{r}41 \\
30 \\
6\end{array}$ & $\star \star\left[\begin{array}{l}240 \\
225 \\
199\end{array}\right]$ * & $\begin{array}{l}27 \\
25 \\
25\end{array}$ & $\begin{array}{l}190-300 \\
180-280 \\
170-250\end{array}$ \\
\hline $\mathrm{T}$ time (ms) & $\begin{array}{l}\text { Severe } \\
\text { Moderate } \\
\text { Mild }\end{array}$ & $\begin{array}{r}41 \\
29 \\
6\end{array}$ & $\star \star\left[\begin{array}{l}71 \\
62 \\
45\end{array}\right]$ $]_{\star}^{\star}$ & $\begin{array}{l}17 \\
16 \\
14\end{array}$ & $\begin{array}{l}39-120 \\
35-106 \\
35-70\end{array}$ \\
\hline
\end{tabular}

QM2, fractional time of maximum of murmur in relation to electromechanical systole; A, apex; B, base; LVET, left ventricular ejection time, corrected according to Meiners. ${ }^{11} \mathrm{U}$ time and $\mathrm{T}$ time are rate corrected according to Bazett. ${ }^{12}$

${ }^{\star} p<0.05,{ }^{\star} p<0.01$.

Table 3 Echocardiographic findings

\begin{tabular}{|c|c|c|c|c|c|}
\hline Variable & Aortic stenosis & No & Mean & $S D$ & Range \\
\hline LVIDed (mm) & $\begin{array}{l}\text { Severe } \\
\text { Moderate } \\
\text { Mild }\end{array}$ & $\begin{array}{r}25 \\
23 \\
4\end{array}$ & $\begin{array}{l}51 \\
54 \\
66\end{array}$ & $\begin{array}{r}9 \\
8 \\
10\end{array}$ & $\begin{array}{l}39-76 \\
35-74 \\
52-73\end{array}$ \\
\hline$($ IVSed + LVPWed)/2(mm) & $\begin{array}{l}\text { Severe } \\
\text { Moderate } \\
\text { Mild }\end{array}$ & $\begin{array}{r}25 \\
21 \\
3\end{array}$ & $\begin{array}{l}15 \cdot 2 \\
14 \cdot 3 \\
13 \cdot 8\end{array}$ & $\begin{array}{l}2.3 \\
2.0 \\
1.0\end{array}$ & $\begin{array}{l}12-20 \\
11-19 \\
13-15\end{array}$ \\
\hline Left ventricular mass (g) & $\begin{array}{l}\text { Severe } \\
\text { Moderate } \\
\text { Mild }\end{array}$ & $\begin{array}{r}25 \\
21 \\
3\end{array}$ & $\begin{array}{l}433 \\
442 \\
532\end{array}$ & $\begin{array}{l}141 \\
124 \\
178\end{array}$ & $\begin{array}{l}263-788 \\
271-738 \\
370-722\end{array}$ \\
\hline LAes (mm) & $\begin{array}{l}\text { Severe } \\
\text { Moderate } \\
\text { Mild }\end{array}$ & $\begin{array}{r}39 \\
31 \\
6\end{array}$ & $\begin{array}{l}41 \\
42 \\
44\end{array}$ & $\begin{array}{l}7 \\
7 \\
6\end{array}$ & $\begin{array}{l}27-58 \\
31-61 \\
38-52\end{array}$ \\
\hline
\end{tabular}

LVIDed, left ventricular end diastolic diameter; IVSed, septal end diastolic thickness; LVPWed, left ventricular posterior wall end diastolic thickness; LAes, left atrial end systolic diameter. 
could be measured. The left ventricle was dilated to more than $55 \mathrm{~mm}$ in $19(37 \%)$ of 52 cases (Table 3$)$. There was no correlation between estimated left ventricular mass and valve area, nor between severity of aortic stenosis and left atrial size.

\section{Radiography}

Aortic calcification was seen in $44(90 \%)$ of 49 cases on the chest $x$ ray in the group with severe, in $23(68 \%)$ of 34 cases in the group with moderate, and in two $(33 \%)$ out of six cases in the group with mild stenosis. The corresponding figures for calcifications on the cineradiography were $49 / 49(100 \%), 33 / 34(97 \%)$, and $5 / 5(100 \%)$.

\section{Coronary angiography}

Of 70 patients $(77 \%)$ who suffered from chest pain $63(90 \%)$ had coronary angiography. Seventeen $(27 \%)$ of these had at least one coronary arterial stenosis reducing the luminal area by $70 \%$ or more. Single vessel disease was found in 10 patients, two and three vessel disease in five and two respectively. Of the remaining $21(23 \%)$ patients without chest pain, $14(67 \%)$ had coronary angiography and none had a stenosis.

\section{Discussion}

Because the patients in this study were selected on account of their apparent need of operation, the frequency of particular symptoms or signs in them should not be taken as being representative of an unselected population of patients with aortic valvar disease. This applies especially to the group with mild stenosis. In four of the six patients in this group the non-invasive results did not indicate a severe stenosis and in one they were contradictory, but the patients were catheterised because of severe symptoms, exercise related dizziness or syncope or left ventricular failure in combination with a murmur of aortic stenosis.

Patients with aortic regurgitation were not excluded because aortic stenosis seldom occurs without any regurgitation in this age group. Patients who before catheterisation were judged to have predominant aortic regurgitation with minimal stenosis were, however, not included.

The severity of an aortic stenosis can be expressed as the pressure difference across the valve or as the calculated valve area. ${ }^{18}$ With aortic regurgitation, the area is underestimated because the flow across the valve is greater than the forward stroke volume measured by the Fick method. Expression of aortic stenosis in terms of valve area does, however, give information about the degree of haemodynamic load imposed by the valve lesion.

\section{CLINICAL AND NON-INVASIVE FINDINGS}

No relation was found between single symptoms and valve area; this accords with other studies. ${ }^{21} 22$ It is not surprising since the symptoms of other diseasefor example, coronary artery disease-may resemble those of aortic stenosis.

The non-invasive findings can be classified according to morphological changes in the aortic valve, haemodynamic effects of obstruction to flow, measures reflecting left ventricular hypertrophy, and of functional capacity.

\section{Morphological changes in the aortic valve}

In $78 \%$ of the whole group and $90 \%$ of those with severe stenosis calcification was seen on the chest $x$ ray. This is slightly less than was reported by Szamosi and Wassberg who found calcification in $91 \%$ of patients with aortic stenosis undergoing operation $^{23}$ but more than that reported by Nakamura et al. ${ }^{6}$ Cineradiography was much more sensitive than the chest $x$ ray, and detected calcification in $99 \%$ of our study group. Increased echodensity at the aortic valves was even more sensitive than cineradiography since it was detected in $100 \%$ of patients, although the severity of aortic stenosis could not be assessed from the extent of cusp separation (which was often undetectable). Therefore fluoroscopy and echocardiography are extremely useful because they can reliably suggest or rule out the possibility of aortic stenosis in the atypical case. $^{24}$

Non-invasive measures of the obstruction to flow

Late peak intensity of the systolic murmur is correlated with severity of aortic stenosis. ${ }^{3525}$ The peak intensity was, however, difficult to identify in our patients because there was considerable beat to beat variation, which was often due to irregular high intensity vibrations occurring within the murmur. In all patients except two, however, the murmur was most intense in late systole. A prolonged left ventricular ejection time and a slow rise of the systolic pulse wave is typically found in valvar aortic stenosis. An appreciable number of our patients, however, had a normal left ventricular ejection time. However, the left ventricular ejection time, the rate corrected upstroke time, and $\mathrm{T}$ time differed considerably in the three groups. The carotid pulse tracing is therefore a useful aid for estimating the severity of aortic stenosis in this age group too. ${ }^{3526}$

\section{Non-invasive variables reflecting left ventricular hypertrophy}

The frequency $(84 \%)$ of electrocardiographic evidence of left ventricular hypertrophy was similar to that reported in other studies. ${ }^{27}$ Only one patient 


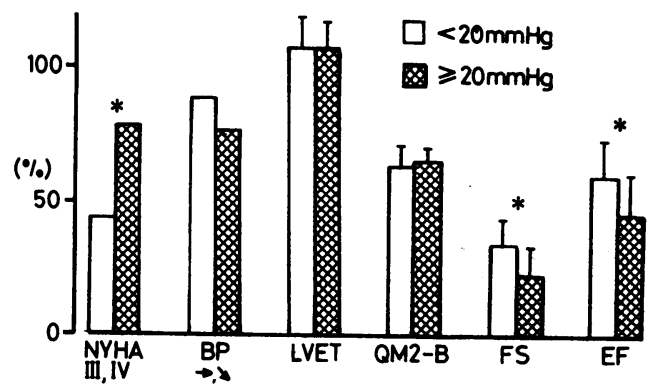

Fig. 7 Comparison between patient groups with left atrial pressure $<20$ and $\geqslant 20 \mathrm{~mm} \mathrm{Hg}$ with regard to symptoms (New York Heart Association III or IV), blood pressure reaction at exercise test ( $B P$ ), left ventricular ejection time ( LVET), time of maximum systolic murmur in relation to electromechanical systole (QM2-B), fractional shortening (FS), and ejection fraction (EF) measured with $M$ mode echocardiography.

had a completely normal electrocardiogram. Left ventricular wall thickness was increased in $90 \%$ of the patients in whom it was possible to define the myocardial borders echocardiographically. This was, however, possible only in $54 \%$ of the patients. The frequency of echocardiographic left ventricular hypertrophy was similar to that observed by others. ${ }^{28}$ Bennett's formula ${ }^{29}$ for estimation of the degree of stenosis from the ratio of wall thickness to left ventricular cavity dimension was not applicable to our patients. It has been suggested that patients with severe aortic stenosis have an increased left atrial size. ${ }^{30}$ This was not true in our patients.

\section{Functional evaluation}

The exercise test was performed by $84 \%$ of the patients. Many were in New York Heart Association functional class III or IV; but with precautions, namely, frequent blood pressure recordings, and interruption of the test when blood pressure fell or dizziness or angina occurred, the tests could be performed safely. As with other observations ${ }^{3132}$ the exercise test gave additional information about the functional capacity. Eight patients in New York Heart Association class III or class IV had only a moderatly reduced work capacity $(50-80 \%$ of the expected) while 12 patients in New York Heart Association class II had a work capacity below $50 \%$ of expected.

\section{FACTORS INFLUENCING THE NON-INVASIVE} FINDINGS

The reason why combinations of non-invasive tests are needed for accurate prediction of severe aortic stenosis is because factors other than the degree of aortic valvar obstruction-notably medication, hy- pertension, left ventricular dysfunction, and coronary artery disease-will affect the measurement of single variables.

Patients treated by $\beta$ receptor blockade or diuretics or both and untreated patients did not differ in regard to the type of blood pressure reaction or the left ventricular ejection time. Arterial hypertension was equally distributed between patients with and without electrocardiographic signs of left ventricular hypertrophy. Hypertension had no demonstrable influence on the correlations between echocardiographic measures of left ventricular hypertrophy and aortic valve area. Genovese et al have reported that patients with aortic stenosis and hypertension have an earlier maximum of the systolic murmur than those without hypertension. ${ }^{33}$ This was not the case in our patients.

To analyse the effect of left ventricular dysfunction we excluded patients with moderate to severe mitral regurgitation and compared the noninvasive findings in patients with a left atrial mean pressure of $20 \mathrm{~mm} \mathrm{Hg}$ or more with patients with lower left atrial pressures (Fig. 7). Only New York Heart Association functional class, echocardiographic fractional shortening, and ejection fraction discriminated between the two groups. Thus in elderly patients it was difficult to determine whether symptoms such as dyspnoea or a reduced exercise tolerance were caused by the aortic stenosis, left ventricular dysfunction, or both.

Both coronary artery disease and aortic valve disease may produce angina. Our patients had a similar frequency of chest pain and coronary artery disease as earlier reported in middle aged patients with aortic stenosis. Coronary artery disease was not found in any patient without angina pectoris which accords with another report. ${ }^{34}$ Hence the indication for coronary angiography in patients without angina is questionable.

To summarise, in elderly patients with aortic stenosis: (a) electrocardiography and chest $x$ ray are useful for routine examination, and normal findings do not exclude severe aortic stenosis; (b) a late maximum of the systolic murmur is characteristic of severe aortic stenosis, even in patients with left ventricular dysfunction or hypertension; $(c)$ in severe aortic stenosis the carotid pulse tracing is often abnormal, and to some extent the degree of abnormality correlates with the severity of stenosis; $(d)$ there is evidence of left ventricular hypertrophy on the electrocardiogram in $80-90 \%$ of cases and by echocardiography in about $90 \%$ of those patients in whom satisfactory recordings are obtained; $(e)$ echodense aortic valves with reduced motility are a reliable echocardiographic indicator of aortic valve disease, which is valuable in atypical cases and for 
the differentiation between subvalvar obstructions and aortic stenosis, but this investigation does not indicate the severity of the disease; $(f)$ coronary artery disease without angina pectoris is very rare and the need for routine coronary angiography in this age group is therefore questionable; $(g)$ the exercise test gives an objective measurement of the physical work capacity - an inadequate blood pressure reaction during exercise is a common finding; $(h)$ when most findings point to severe aortic stenosis the absence of a single symptom or non-invasive sign does not exclude this diagnosis.

This study was supported by grants from the Swedish National Association against Heart and Chest Diseases, the County Council of Östergötland, and the Swedish Medical Research Council.

\section{References}

1 Takeda J, Warren R, Holzmann D. Prognosis of aortic stenosis. Special reference to indications for operative treatment. Arch Surg 1963; 87: 931-6.

2 Ross J Jr, Braunwald E. Aortic stenosis. Circulation 1968; suppl V-61: 37-8.

3 Bonner AJ Jr, Sacks HN, Tavel ME. Assessing the severity of aortic stenosis by phonocardiography and external carotid pulse recordings. Circulation 1973; 68: 247-52.

4 Cousins AL, Eddleman EE Jr, Reeves TJ. Prediction of aortic valvular area and gradient by noninvasive techniques. Am Heart $\mathcal{F}$ 1978; 95: 308-15.

5 Voelkel AG, Kendrick M, Pietro DA, et al. Noninvasive tests to evaluate the severity of aortic stenosis. Limitations and reliability. Chest 1980; 77: 155-60.

6 Nakamura T, Hultgren HN, Schettigar UR, Fowles RE. Noninvasive evaluation of the severity of aortic stenosis in adult patients. Am Heart $\mathcal{f}$ 1984; 107: 959-66.

7 New York Heart Association. Diseases of the heart and blood vessels. 7th ed. Boston: Little Brown, 1973.

8 Rose GA, Blackburn H. Cardiovascular survey methods. WHO Monogr Ser 1968; 56: 1-188.

9 Strandell T. Heart rate and work load at maximal working intensity in old men. Acta Med Scand 1964; 176: $301-18$.

10 Áström H, Jonsson B. Design of exercise test, with special reference to heart patients. Br Heart $\mathcal{F}$ 1976; 38: 289-96.

11 Meiners S. Messmethoden zur Analyse der Herz- und Kreislaufdynamik. In: Weber A, Blumberger KJ, eds. Kreislaufmessungen. Augsburg München-Gräfelfing, West Germany: Werk-Verlag, 1958: 84-98.

12 Bazett HC. Analysis of the time relations of the electrocardiogram. Heart 1920; 7: 353-70.

13 Weissler AM, Harris LC, White GD. Left ventricular ejection time index in man. I Appl Physiol 1963; 18: 919-23.

14 Tavel ME. Clinical phonocardiography and external pulse recording. Chicago: Year Book Medical Publishers, 1977: 170-3.

15 Cullhed I. Aortic stenosis. Uppsala: Almqvist and Wiksell, 1964: 95-6.
16 Sahn DJ, DeMaria A, Kisslo J, Weyman A. The committee on $\mathrm{M}$-mode standardization of the American Society of Echocardiography. Recommendations regarding quantitation in M-mode echocardiography: results of a survey of echocardiographic measurements. Circulation 1978; 58: 1072-83.

17 Bennett DH, Evans DW. Correlation of left ventricular mass determined by echocardiography with vectorcardiographic and electrocardiographic voltage measurements. Br Heart $\mathcal{F}$ 1974; 36: 981-7.

18 Gorlin R. Shunt flows and valve areas. In: Zimmerman HA, ed. Intravascular catheterization. Springfield, Illinois: Charles C Thomas, 1966: 545-82.

19 Winer BJ. Statistical principles in experimental design. New York: McGraw-Hill, 1971.

20 Nordesjö LO, Landelius J. Clinical evaluation of work capacity [Abstract]. Scand $\mathcal{F}$ Clin Lab Invest 1975; 35: suppl 143: 64 .

21 Cheitlin MD, Gertz EW, Brundage BH, Carlson CJ, Quash JA, Bode RS Jr. Rate of progression of severity of valvular aortic stenosis in the adult. Am Heart $\mathcal{F}$ 1979; 98: 689-700.

22 Chizner MA, Peaarle DL, deLeon AC Jr. The natural history of aortic stenosis in adults. Am Heart 3 1980; 99: 419-24.

23 Szamosi A, Wassberg B. Radiologic detection of aortic stenosis. Acta Radiol (Diagn) 1983; 24: 201-7.

24 Morgan DJR, Hall RJC. Occult aortic stenosis as cause of intractable heart failure. $\mathrm{Br}$ Med $\mathcal{F}$ 1979; 1: 784-7.

$25 \mathrm{Nesje} \mathrm{OA}$. Severity of aortic stenosis assessed by carotid pulse recordings and phonocardiography. Acta Med Scand 1978; 204: 321-30.

26 Eddleman EE Jr, Frommeyer WB Jr, Lyle DP, Bancroft WH Jr, Turner ME Jr. Critical analysis of clinical factors in estimating severity of aortic valve disease. $\mathrm{Am}$ $f$ Cardiol 1973; 31: 687-95.

27 Gardin JM, Kaplan KJ, Meyers SN, Talano JV. Aortic stenosis: can severity be reliably estimated noninvasively? Chest 1980; 77: 130-1.

28 Lesbre JP, Scheublé C, Kalisa A, et al. Apport de l'echocardiographie au diagnostic des sténoses aortiques valvulaires sevéres de l'adulte. Arch Mal Coeur 1983; 76: 1-12.

29 Bennett DH, Evans DW, Raj MVJ. Echocardiographic left ventricular dimensions in pressure and volume overload. Their use in assessing aortic stenosis. $\mathrm{Br}$ Heart $\mathcal{F}$ 1975; 37: 971-7.

30 Chandraratna PAN, Aronow MS, Aronow WS. Significance of echocardiographic left atrial enlargement in aortic stenosis. Clin Cardiol 1982; 5: 520-2.

31 Persson S. Aortic valvular disease. A longitudinal, hemodynamic and clinical study. Lund: Studentlitteratur, 1974.

32 Goldman L, Cook EF, Mitchell N, Flatley M, Sherman H, Cohn PF. Pit-falls in the serial assessment of cardiac functional status. F Chronic Dis 1982; 36: 763-71.

33 Genovese B, Ronan JA, Applefeld MM, Perloff JK. Effect of hypertension on the clinical assessment of severity of aortic stenosis [Abstract]. Circulation 1977; 55 (suppl 57): 260.

34 Exadactylos N, Sugrue DD, Oakley CM. Prevalence of coronary artery disease in patients with isolated aortic valve stenosis. Br Heart $\mathcal{F}$ 1984; 51: 121-4. 